\title{
ELISA Measurement of Mouse IL-2
}

Guo N. Huang*

Program in Biochemistry, Cellular and Molecular Biology, Johns Hopkins University School of Medicine, Baltimore, USA

*For correspondence: guo.n.huang@gmail.com

[Abstract] Interleukin-2 (IL-2) is a cytokine secreted by T cells that is essential for immune system activation. This protocol is routinely used for quantification of IL-2 concentration in the supernant of cultured lymphocytes under various stimulations and co-culturing conditions. Following slight modification and optimization, this protocol can also be adapted to quantitatively measure other secreted proteins and bio-molecules.

\section{Materials and Reagents}

1. BD OptEIA ELISA set including IL-2 standard, capture antibody, detection antibody/enzyme reagent (BD Biosciences, catalog number: 555148)

2. Assay diluent (BD Biosciences, catalog number: 555213) or medium made of half RPM1640/10\% FCS/PS and half RPM1640.

3. Substrate solution (BD Biosciences, catalog number: 555214)

4. $\mathrm{NaCl}$

5. $\mathrm{NaHCO}_{3}$

6. $\mathrm{Na}_{2} \mathrm{CO}_{3}$

7. $\mathrm{Na}_{2} \mathrm{HPO}_{4}$

8. $\mathrm{KH}_{2} \mathrm{PO}_{4}$

9. $\mathrm{KCl}$

10. Tween-20

11. $\mathrm{H}_{2} \mathrm{SO}_{4}$

12. Coating buffer (see Recipes)

13. Wash buffer (PBST, pH 7.0) (see Recipes)

14. Stop solution (see Recipes)

\section{Equipment}

1. ELISA plates (100 plates/case) (BD Biosciences, catalog number: 353279) and plate sealers (100 plates/case) (PGC Scientifics, catalog number: 045-826) 
2. 96-well plates for dilution (SARSTEDT AG, catalog number: 82.1583)

3. Multichannel pipette and pipette tips (eBay, catalog number: RT-L200F)

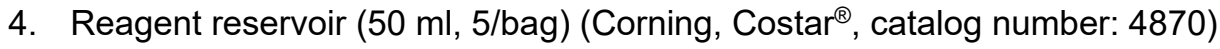

5. ELISA micro plate reader

\section{Procedure}

1. Prepare coating buffer. Dilute capture antibody in coating buffer (1:250 for lot \#0000052895) and add $50 \mu$ lo each well. Seal plates and incubate overnight at $4{ }^{\circ} \mathrm{C}$.

2. Wash 3 times.

3. Block: $200 \mu \mathrm{l}$ Assay diuent to each well. Room temperature (RT) $1 \mathrm{~h}$.

4. Wash 3 times.

5. Add $50 \mu \mathrm{l}$ standard or sample to each well. RT $2 \mathrm{~h}$.

Standard: make $800 \mathrm{pg} / \mathrm{ml}$ standard in assay diluent from original $135 \mathrm{ng} / \mathrm{ml}$ stock and aliquote $0.4 \mathrm{ml}$ each (enough for one assay) and store at $-80^{\circ} \mathrm{C}$.

$135 \mathrm{ng} / \mathrm{ml} \times 23.7 \mu \mathrm{l}=800 \mathrm{p} / \mathrm{ml} \times(3.98+0.0237) \mathrm{ml}$

\begin{tabular}{lllllll}
$\mathrm{Pg} / \mathrm{ml}$ & 0 & 50 & 100 & 200 & 400 & 800 \\
\hline $800 \mathrm{pg} / \mathrm{ml}(\mu \mathrm{l})$ & 0 & 9.38 & 18.8 & 37.5 & 75 & 150 \\
Diluent $(\mu \mathrm{l})$ & 150 & 140.6 & 131.2 & 112.5 & 75 & 0
\end{tabular}

$50 \mu$ each

6. Wash 5 times.

7. 15 min before use, dilute detection antibody and avidin-conjugated HRP in Assay diluent (1:330 for lot \#0000052895, $8 \mu \mathrm{l} \mathrm{each/6} \mathrm{ml} \mathrm{for} \mathrm{one} \mathrm{96-well} \mathrm{plate).} \mathrm{RT} 1 \mathrm{~h}$.

8. Wash 7 times.

9. Prepare substrate solution (1:1 of $A$ and $B, 6 \mathrm{ml}$ for one 96 -well plate). Add $50 \mu \mathrm{l}$ to each well. RT 30 min in dark.

10. Add $25 \mu \mathrm{l}$ stop solution. Read at $450 \mathrm{~nm}$ and $570 \mathrm{~nm}$ within $30 \mathrm{~min}$.

\section{$\underline{\text { Recipes }}$}

1. Coating buffer (0.1 M carbonate buffer) ( $\mathrm{pH} 9.5)$

$4.20 \mathrm{~g} \mathrm{NaHCO}_{3}$

$1.28 \mathrm{~g} \mathrm{Na}_{2} \mathrm{CO}_{3} / 0.5 \mathrm{~L}$

Use within 7 days and store at $4{ }^{\circ} \mathrm{C}$.

2. Wash buffer (PBST, pH 7.0)

$16 \mathrm{~g} \mathrm{NaCl}$

$2.32 \mathrm{~g} \mathrm{Na}_{2} \mathrm{HPO}_{4}$ 
$0.4 \mathrm{~g} \mathrm{KH}_{2} \mathrm{PO}_{4}$

$0.4 \mathrm{~g} \mathrm{KCl}, 1 \mathrm{ml}$

Tween-20 / 2 L per two 96-well plates

Use within 3 days and store at $4{ }^{\circ} \mathrm{C}$.

3. Stop solution

$2 \mathrm{~N} \mathrm{H}_{2} \mathrm{SO}_{4}(1 \mathrm{M})$

\section{Acknowledgments}

This work was supported by National Institute on Drug Abuse (NIDA; DA00266, DA10309) and the National Institute of Mental Health (NIMH; MH068830).

\section{References}

1. Huang, G. N., Huso, D. L., Bouyain, S., Tu, J., McCorkell, K. A., May, M. J., Zhu, Y., Lutz, M., Collins, S., Dehoff, M., Kang, S., Whartenby, K., Powell, J., Leahy, D. and Worley, P. F. (2008). NFAT binding and regulation of T cell activation by the cytoplasmic scaffolding Homer proteins. Science 319(5862): 476-481. 